\title{
KEBIJAKAN PENGEMBANGAN SUMBER DAYA MANUSIA DI KOTA KEDIRI DALAM RANGKA PENINGKATAN INDEKS PEMBANGUNAN MANUSIA
}

\author{
Suwarno \\ Fakultas Ilmu Sosial dan Politik, Universitas Kadiri \\ E-mail: suwarno@unik-kadiri.ac.id
}

\begin{abstract}
The purpose of this study is to explore the relationship between human resource development in order to improve the 2014-2018 human development index in Kadiri City. Previous studies state that there is no significant relationship between economic growth and the process of human development. Economic growth does not contribute to human development. However, this is not the case in Kediri City. By using descriptive research methods documentation and literature. Data obtained using the method of documentation from formal government sources that have been published so that it can be categorized as valid and responsive data. The analysis was carried out by describing human resource development policies in terms of education, health, income level, employment, and other aspects that could increase the human development index (HDI) in Kediri City. Based on the results of the study revealed that the human resource development policy in the City of Kediri in the context of increasing the human development index (HDI) has been going very well, it is proven, the HDI of the City of Kediri for the last five years has always been above the East Java and National average. The success of the City of Kediri in increasing the HDI is due to the seriousness of the local government in increasing participation rates and the level of public education. Local governments are also serious in improving public health. In addition, the city government of Kediri also increased community income, poverty alleviation, increased GRDP, and various other businesses that were simultaneous and continued to manage. Furthermore, new findings from this study can contribute to stakeholders in taking strategic policy steps and suggesting that local governments increase the human development index (HDI) in their region by encouraging the development of human resources.
\end{abstract}

Keywords: Human development index, Resources, education, health

\section{PENDAHULUAN}

Kualitas pembangunan sumber daya manusia adalah tema utama dalam setiap program pertumbuhan ekonomi pembangunan. Dengan kata lain, indeks pembangunan manusia dianggap sangat penting bagi perekonomian karena dengan melihatnya, tingkat perkembangan negara manapun dapat terlihat. Ini didasarkan pada indeks pendidikan, indeks kesehatan, dan Pendapatan Domestik Bruto (PDB) sehingga tingkat perkembangan suatu wilayah atau daerah ditahun yang berbeda penting untuk mempertimbangkan HDI-nya (Javaid, 2019). Tujuan pembangunan milenium (Millenium Development Goals/MDG's), disepakati oleh pemimpin dunia dalam KTT 2000. MDG's adalah bentuk komitmen masyarakat global yang menjadikan pembangunan sosial dan ekonomi secara berkelanjutan sebagai prioritas utama (Basrowi and Suseno, 2016). Dari dua dekade terakhir, Program Pembangunan Perserikatan Bangsa-Bangsa (UNDP) merilis laporan tahunan yang menyediakan kerangka kerja untuk pengukuran indeks pembangunan manuia (IPM) IPM membantu dalam perbandingan lintas negara, melalui pengembangan tingkat (Hou, Walsh, and Zhang, 2015); (United Nations Development Programme (UNDP), 2014) 


\section{SUWARNO \\ Kebijakan Pengembangan Sumber Daya Manusia Di Kota Kediri Dalam Rangka Peningkatan Indeks Pembangunan Manusia}

Pilihan yang paling utama adalah pengetahuan dan akses terhadap sumber daya yang dibutuhkan baik sumber daya manusia maupun sumber daya lainnya sehingga dapat hidup dengan sejahtera (Dinas Kesehatan Kota Kediri, 2018)."

Indeks Pembangunan Manusia (IPM) pada hakikatnya mengukur pencapaian pembangunan manusia dengan sejumlah dimensi kualitas hidup. Untuk mengukur dimensi hidup layak digunakan indikator kemampuan daya beli masyarakat terhadap kebutuhan hidup yang layak yang diperkirakan dihitung dari rata-rata besarnya pengeluaran per kapita (Databook, 2018)."

Dewasa ini persoalan mengenai capaian pembangunan manusia telah menjadi perhatian para penyelenggara pemerintahan. Berbagai ukuran pembangunan manusia dibuat namun tidak semuanya dapat digunakan sebagai ukuran standar yang dapat dibandingkan antar wilayah atau antar negara. Oleh karena itu Badan Perserikatan Bangsa-Bangsa (PBB) menetapkan suatu ukuran standar pembangunan manusia yaitu indeks pembangunan manusia (IPM) atau Human Development Index (HDI) (Basrowi and Suseno, 2016).

Kebijakan United Nations Development Programme (UNDP, 2004) dalam buku" The Economics of Democracy: Financing Human Development in Indonesia (Badan Pusat Statistik 2017)" menekankan pentingya aspek pembiayaan bagi masyarakat miskin. Secara eksplisit UNDP menyarankan pentingya memberikan prioritas investasi yang lebih tinggi pada upaya pembangunan kualitas manusia (Maryani, 2010). Sebuah studi tentang pembangunan ekonomi berdasarkan 23 sampel kabupaten/kota di Indonesia pada tahun 2017 mengungkapkan bahwa moderasi antara indeks pembangunan manusia melalui dana otonomi khusus berpengaruh negatif signifikan terhadap pertumbuhan ekonomi. Hal ini mengindikasi penggunaan dana otonomi khusus untuk indeks pembanguan manusia masih cukup tinggi, sehingga ke depannya diharapkan perlu adanya alokasi dana yang sesuai dengan kebutuhan di daerah, sehingga dana otonomi khusus dapat efektif dan lebih efisien (Iskandar, 2017).

Pemerintah daerah Kota Kediri telah menggunakan Anggaran Pendapatan dan Belanja Daerah (APBD) dalam rangka membiayai pembangunan di sektor pengembangan sumber daya manusia yang tercermin pada realisasi belanja daerah untuk bidang pendidikan dan kesehatan. Penduduk yang miskin di Kota Kediri nampaknya memiliki keterbatasan dalam mengakses kebutuhan dalam bidang pendidikan dan kesehatan. Karenanya implikasi tingginya angka kemiskinan akan dapat menurunkan IPM (Maryani, 2010).

Indeks Pembangunan Manusia (IPM) atau Human Development Index (HDI) dibentuk berdasarkan empat indikator yaitu angka harapan hidup, angka melek huruf, rata-rata lama sekolah dan kemampuan daya beli. Indikator angka harapan hidup merepresentasikan dimensi umur panjang dan sehat. Selanjutnya, angka melek huruf dan rata-rata lama sekolah mencerminkan output dari dimensi pengetahuan. Adapun indikator kemampuan daya beli digunakan untuk mengukur dimensi hidup layak (Nevi, 2015).

Luasnya cakupan pembangunan manusia menjadikan peningkatan IPM Kota Kediri sebagai manifestasi dari pembangunan manusia yang dapat ditafsirkan sebagai keberhasilan Kota Kediri dalam meningkatkan kemampuan dalam memperluas pilihan-pilihan (enlarging the choices of the people). Alasan Kota Kediri sebagai objek penelitian adalah karena terdapat dua faktor penting dalam pembangunan yang sangat efektif bagi pembangunan manusia di Kota Kediri yaitu pendidikan dan kesehatan. Dua faktor penting ini merupakan kebutuhan dasar manusia yang perlu dimiliki agar mampu meningkatkan potensinya. Umumnya, semakin tinggi kapabilitas dasar yang dimiliki masyarakat Kota Kediri, semakin tinggi pula peluang untuk meningkatkan potensi warga di Kota Kediri itu sendiri. 
Namun seiring kemajuan ilmu pengentahuan dan teknologi, peran sentral pemerintah dalam proses pengembangan pembangunan manusia menjadi cukup pelik untuk dilakukan secara maksimal. Begitu pula untuk daerah dan wilayah yang lain. Keberhasilan indeks pembangunan manusia di Kota Kediri tidak dapat begitu saja menjadi dimensi yang kuat untuk ke depannya. Dibutuhkan langkah-langkah strategis untuk keberlanjutan. Berdasarkan penelitian yang dilakukan Khan, Ju, dan Hassan (2018) menjelaskan bahwa pertumbuhan ekonomi tidak berkontribusi pada pengembangan manusia di Pakistan. Lebih lanjut, dijelaskan pula bahwa urbanisasi berkontribusi positif bagi perkembangan manusia. Selain itu, nampaknya terorisme memperburuk indeks pembangunan manusia (Khan, Ju, and Hassan, 2018). Hal ini mengindikasi bahwa setiap daerah ataupun wilayah membutuhkan dimensi -dimensi yang unggul dan mempunyai bukti empris dan valid untuk mempromosikan indeks pembangunan manusia. Secara khusus, ini dilakukan sebagai wacana dalam menghadapi Agenda Pembangunan Berkelanjutan tahun 2030. Penelitian ini mengusulkan pengembangan sumber daya manusia untuk meningkatkan indeks pembangunan manusia di Indonesia dengan Kota Kediri sebagai sampel penelitian karena secara empris menunjukkan perkembangan indeks pembanguan manusai ke arah yang lebih baik.

\section{TINJAUAN LITERATUR}

\section{Konsep Indeks Pembangunan Manusia}

Pembangunan manusia merupakan suatu proses untuk memperluas pilihanpilihan bagi penduduk. Sedangkan upaya pembangunan ditujukan sebagai sarana (principal means) untuk mencapai tujuan pembangunan manusia. Ada empat dimensi yang utama, yaitu produktivitas, pemerataan, kesinambungan, dan pemberdayaan (United Nations Development Programme (UNDP) 2014);(Basrowi and Suseno 2016).
Dijelaskan bahwa IPM merupakan indeks komposit yang meliputi tiga bidang pembangunan manusia meliputi indeks pendidikan, indeks kesehatan, dan indeks ekonomi. Tiga indikator tersebut yaitu: indikator kesehatan, tingkat pendidikan, dan indikator ekonomi. Untuk kualitas fisik berupa angka harapan hidup, sedangkan kualitas non fisik berupa lamanya rata-rata penduduk bersekolah dan angka melek huruf, serta kemampuan ekonomi yaitu pengeluaran riil per kapita (Maryani, 2010).

Pada dasarnya IPM adalah indikator untuk mengukur aspek kualitas dari hasil pembangunan ekonomi, yakni derajat perkembangan manusia yang didasarkan pada tiga unsur yaitu kesehatan, pendidikan yang dicapai, dan standar kehidupan atau sering disebut ekonomi (Kacaribu, 2013).

Sebuah studi mengungkapkan bahwa IPM berperan penting dalam pembangunan perekonomian modern. Adanya IPM mampu mendorng mutu penduduk yang baik akan mampu untuk berinovasi serta mengembangkan faktor-faktor produksi dan juga mengakibatkan jumlah penduduk akan tinggi pula sehingga akan menaikkan tingkat konsumsi (Syarifah, 2012).

Melliana dan Zain menjelaskan bahwa untuk mengukur IPM maka metode perhitungan Indeks Pembangunan Manusia (IPM) dilakukan dengan mengukur lamanya hidup dukur dengan harapan hidup saat lahir, tingkat pendidikan diukur dengan kombinasi antar angka melek huruf pada penduduk dewasa (dengan bobot dua per tiga) dan rata-rata lama sekolah (dengan bobot sepertiga), dan tingkat kehidupan yang layak diukur dengan pengeluaran perkapita yang telah disesuaikan (Melliana and Zain, 2013).

Lebih lanjut hasil temuan Susanto, Budi dan Rachmawati menyebutkan bahwa keberhasilan pembangunan manusia dinilai secara parsial dengan melihat seberapa besar permasalahan yang paling mendasar di masyarakat. Permasalahan yang dimaksud adalah persoalan pegnentasan kemiskinan, angka pengangguran, tingginya buta huruf, ketahanan pangan masyarakat, serta 


\section{SUWARNO \\ Kebijakan Pengembangan Sumber Daya Manusia Di Kota Kediri Dalam Rangka Peningkatan Indeks Pembangunan Manusia}

penegakan demokrasi. Untuk mengatasi persoalan yang demikian, ukuran pembangunan manusia dibuat akan tetapi tidak semuanya dapat digunakan di semua negara. Walaupun demikian dapat dijadikan sebagai ukuran standar yang dapat dibandingkan antar wilayah atau antar negara. Oleh karena itu, Badan Perserikatan Bangsa-Bangsa (PBB) menetapkan suatu ukuran standar pembangunan manusia yang dapat digunakan secara luas yaitu IPM atau Human Development Index (HDI) (Susanto, Budi, and Rachmawati, 2010)

Indeks Pembangunan Manusia berfokus pada hal-hal yang lebih sensitif dan dapat mengetahui kondisi pembangunan di daerah. Pertama adalah karena dapat menajdi indikator dalam mengukur keberhasilan pembangunan kualitas manusia. Kedua, IPM mampu menjelaskan bagaimana manusia mempunyai kesempatan untuk mengakses hasil dari proses pembangunan, sebagai bagian dari haknya seperti dalam memperoleh pendapatan, kesehatan, pendidikan, dan kesejahteraan. Dan terakhir adalah sebagai salah satu ukuran kinerja daerah, khususnya dalam hal evaluasi terhadap pembangunan kualitas hidup masyarakat/penduduk. Namu pada perkembanganya, IPM belum tentu mencerminkan kondisi sesungguhnya pembangunan kualitas hidup manusia (Kintamani 2008).

Badan Pusat Statistik (BPS) menejlaskan bahwa IPM mengacu pada pengukuran capaian pembangunan manusia berbasis sejumlah komponen dasar kualitas hidup. Pertama yaitu angka harapan hidup untuk mengukur capaian di bidang kesehatan. Kedua, angka melek huruf dan rata-rata lama menempuh pendidikan formal untuk mengukur capaian di bidang pendidikan. Dan ketiga, standar kehidupan yang layak, yang diindikasikan dengan logaritma normal dari produk domestik bruto perkapita penduduk dalam paritas daya beli (United Nations Development Programme (UNDP), 2014).
Tabel 1. Nilai Perhitungan Komponen IPM

\begin{tabular}{|l|l|l|}
\hline Indikator IPM & \multicolumn{1}{|c|}{$\begin{array}{c}\text { Nilai } \\
\text { Minimal }\end{array}$} & $\begin{array}{c}\text { Nilai } \\
\text { Maksimal }\end{array}$ \\
\hline $\begin{array}{l}\text { Angka harapan } \\
\text { hidup }\end{array}$ & 0 & 85 \\
\hline $\begin{array}{l}\text { Angka melek } \\
\text { huruf }\end{array}$ & 0 & 100 \\
\hline $\begin{array}{l}\text { Rata-rata lama } \\
\text { sekolah }\end{array}$ & 0 & 15 \\
\hline $\begin{array}{l}\text { Purchasing } \\
\text { power parity }\end{array}$ & 360.000 & 737.720 \\
\hline
\end{tabular}

Sumber: Sjafari, dkk., 2015

Penerapan kategori IPM didasarkan pada sekala 0,0 s.d. 1,0 yang terdiri atas:

Kategori rendah : nilai IPM 0,0--0,5

Kategori Menengah : nilai IPM antara 0,51--0,79

Kategori Menengah : nilai IPM antara 0,81--1,0

Sumber: (United Nations Development

Programme (UNDP), 2014).

Menurut Amartya Sen dan seorang ekonom Pakistan Mahbub Ul Haq, serta dibantu oleh Gustav Ranis dari Yale University dan Lord Meghnad Desai dari London School of Economics (United Nations Development Programme (UNDP), 2014). IPM mengukur pencapaian rata-rata sebuah negara dalam tiga capaian pembangunan manusia. Pertama adalah kemapuan untuk hidup yang sehat dan panjang umur dengan mengukur harapan hidup saat kelahiran. Kedua, pengetahuan dengan mengukur angka tingkat baca tulis pada orang dewasa (bobotnya dua per tiga) dan kombinasi pendidikan dasar, menengah , atas gross enrollment ratio (bobot satu per tiga). Dan ketiga adalah standard kehidupan yang layak diukur dengan logaritma natural dari produk domestik bruto per kapita dalam paritasi daya beli.

Salah satu alat ukur yang dianggap dapat merefleksikan status pembangunan manusia adalah Human Development Index (HDI) atau IPM. IPM merupakan suatu indeks komposit yang mencakup tiga bidang pembangunan manusia yang dianggap sangat mendasar yaitu usia hidup (longevity), pengetahuan (knowledge), dan standar hidup layak (decent living). 


\section{Penyempurnaan metode IPM}

Perkembangan Metodologi IPM pada tahun 2010, UNDP memperkenalkan penghitungan IPM dengan metode modern. Penyempurnaannya adalah pada Komponen IPM yang digunakan AHH, AMH, Kombinasi APK, PDB per Kapita. Tahun 2010 UNDP merubah metodologi: 1. Komponen IPM yang digunakan AHH, HLS, RLS, PNB per Kapita 2. Agregasi indeks menggunakan rata- rata geometrik 2011. Penyempurnaannya yaitu mengganti tahun dasar PNB per kapita dari tahun 2008 menjadi tahun 2005-2014. Beberapa indikator sudah tidak tepat untuk digunakan dalam penghitungan IPM. Angka Melek Huruf (AMH) sudah tidak relevan dalam mengukur pendidikan secara utuh karena tidak dapat menggambarkan kualitas pendidikan. Selain itu, karena AMH di sebagian besar daerah sudah tinggi, sehingga tidak dapat membedakan tingkat pendidikan antardaerah dengan baik. Produk Domestik Bruto (PDB) per kapita tidak dapat menggambarkan pendapatan masyarakat pada suatu wilayah. Kedua, Penggunaan rumus rata-rata aritmatik dalam penghitungan IPM menggambarkan bahwa capaian yang rendah di suatu dimensi dapat ditutupi oleh capaian tinggi dimensi lain (Nevi, 2015).

Keunggulan metode ini jauh lebih tepat dan dapat membedakan dengan baik (diskriminatif) yaitu dengan memasukkan Rata-rata Lama Sekolah dan angka Harapan Lama Sekolah, bisa diperoleh ilustrasi yang jauh lebih relevan dalam pendidikan. PNB menggantikan PDB karena lebih menggambarkan pendapatan masyarakat pada suatu wilayah. Dengan menggunakan rata-rata geometric maka IPM dapat dipahami sebagai capaian satu dimensi tidak dapat ditutupi oleh capaian di dimensi lain. Artinya, untuk mewujudkan pembangunan manusia yang baik, ketiga dimensi harus memperoleh perhatian yang sama besar karena sama pentingnya (Nevi, 2015)..
Apabila ditabulasikan, perbedaan metode penghitungan IPS tahun 1990 dan 2010 tampak sebagai berikut.

Tabel 2. Perbedaan metode penghitungan IPS tahun 1990 dan 2010

\begin{tabular}{|c|c|}
\hline Metode IPM 1990 & Metode IPM 2010 \\
\hline Angka Harapan & Angka Harapan \\
Hidup saat Lahir & Hidup saat Lahir \\
(AHH) & (AHH) \\
\hline Angka Melek & Harapan Lama \\
Huruf (AMH) & Sekolah (HLS) \\
Rata-rata Lama & Rata-rata Lama \\
Sekolah (RLS) 15 & Sekolah (RLS) 25 \\
th + & th + \\
\hline Pengeluaran per & Pengeluaran per \\
Kapita & Kapita Disesuaikan: \\
Disesuaikan: & 96 Komoditas PPP \\
27 Komoditas PPP & \\
\hline Agregasi Indeks: & Rata-rata \\
Rata-rata Hitung & Geometrik \\
\hline Reduksi Shortfall & Pertumbuhan \\
(RSF) & Aritmatik \\
\hline
\end{tabular}

Sumber: Power Point Sosialisasi

Penghitungan IMB metode baru, BPS 2014

\section{METODE PENELITIAN}

Jenis penelitian yang digunakan adalah deskriptif explanatory yaitu penelitian yang menjelaskan atau mendeskripsikan konsep atau gabungan antara beberapa konsep secara mendetail (Singarimbun and Effendi, 1989).

Lokasi kegiatan di Kota Kediri Jawa Timur. Penelitian dilakukan selama 4 (Empat) bulan Mei-Agustus tahun 2019. Dalam penelitian ini jenis data yang diperlukan adalah data primer yang diperoleh langsung tanpa perantara orang atau lembaga lain sebagai pihak ketiga. Jenis data primer yang hendak digali dalam penelitian ini yaitu: seluruh data capaian pembangunan di bidang sosial dan ekonomi dan seluruh data tersebut secara yang langsung digunakan untuk menjawab rumusan masalah penelitian. Mengingat studi ini hanya menekankan Indek pembangunan Manusia (IPM) di bidang ekonomi yang, maka data primer yang 


\section{SUWARNO \\ Kebijakan Pengembangan Sumber Daya Manusia Di Kota Kediri Dalam Rangka Peningkatan Indeks Pembangunan Manusia}

sangat mendukung dalam menjawab rumusan masalah adalah data capaian pembangunan di bidang ekonomi, kaitannya dengan pertumbuhan ekonomi, daya beli, jumlah pengangguran, kemiskinan, kesehatan, dan lain-lain. Selain itu juga digali data dokumentasi yang diperoleh dari publikasi BPS, dinas kesehatan, Sekretariat Daerah, Dinas ketenagakerjaan, Dinas perekonomian, dan perindustrian. Selain itu juga dilakukan telaah dokumen dilakukan terhadap peraturaan-peraturaan dan ketentuan undang-undang, serta kebijaksanaan-kebijaksanaan yang berkaitan peningkatan IPM di Kota Kediri.

Penelitian ini lebih fokus pada IPM di bidang ekonomi, maka IMP Ekonomi merupakan fungsi dari Pengeluaran pemerintah di bidang penanggulangan kemiskinan, peningkatan daya beli, pembukaan lapangan kerja, dan berbagai program pro-poor yang dilakukan oleh Kota Kediri dan lain-lain

\section{HASIL PENELITIAN \\ Gambaran Umum Kota Kediri}

Kota Kediri mempunya visi yaitu, "Mewujudkan Kota Kediri unggul dan makmur dalam harmoni." Adapun Misi Kota Kediri. Pertama, mewujudkan tata kelola pemerintahan yang bersih, transparan dan berintegritas berorientasi pada pelayanan prima dan teknologi informasi. Kedua, mewujudkan SDM yang berkualitas dan berdaya kompetitif berdasarkan nilai agama dan budaya. Ketiga, memperkuat pertumbuhan daerah berbasis potensi daerah dan pengembangan bidang ekonomi yang berkeadilan. Keempat, mewujudkan Kota Kediri yang aman, nyaman, dan berwawasan lingkungan yang dikelola (Kotakediri.go.id, 2018)."

Luas wilayah Kota Kediri adalah $63.404 \mathrm{~km} 2$, administrasi terbagi menjadi tiga, yaitu Kecamatan Mojoroto, Kecamatan Kota dan Kecamatan Pesantren, dan 46 Kelurahan. Kecamatan Mojoroto dengan wilayah yang luas 24,6 km2 terdiri dari 14 Kelurahan, Kota Kota terdiri dari 17
Kelurahan dengan wilayah yang luas 14,9 km2, dan Kecamatan Pesantren dengan wilayah yang luas 23,9 km2 terdiri dari 15 Kelurahan (Kotakediri.go.id, 2018). Berikut ini kecamatan dan keluran di Kota Kediri:

\section{Tabel 3. Luas Wilayah Kota Kediri}

\section{Menurut Kecamatan dan Kelurahan}

\begin{tabular}{|c|c|c|c|c|c|c|}
\hline Kode & $\begin{array}{l}\text { Kecamatan / } \\
\text { Kelurahan }\end{array}$ & $\begin{array}{l}\text { Luas } \\
(\mathrm{km} 2)\end{array}$ & $\begin{array}{l}\text { Kecamatan / } \\
\text { Kelurahan }\end{array}$ & $\begin{array}{l}\text { Luas } \\
\text { (km2) }\end{array}$ & \begin{tabular}{|l|} 
Kecamatan / \\
Kelurahan
\end{tabular} & \begin{tabular}{|l|} 
Luas \\
(km2)
\end{tabular} \\
\hline & \begin{tabular}{|l|} 
Kec. Kota \\
\end{tabular} & 14,90 & \begin{tabular}{|l|} 
Kec. Pesantren \\
\end{tabular} & 23.903 & \begin{tabular}{|l|} 
Kec.Mojoroto \\
\end{tabular} & 24.601 \\
\hline 001 & Manisrenggo & 1,764 & Blabak & 3,354 & Pojok & 5,153 \\
\hline 002 & Rejomulyo & 1,670 & Bawang & 3,449 & Campurejo & 1,409 \\
\hline 003 & Ngronggo & 2,585 & Betet & 1,691 & Tamanan & 1,077 \\
\hline 004 & Kaliombo & 0,958 & Tosaren & 1,361 & Banjarmlati & 0,954 \\
\hline 005 & Kampungdalem & 0,332 & Banaran & 0,974 & Bandar Kidul & 1.299 \\
\hline 006 & Setonopande & 0,383 & Ngletih & 1,237 & Lirboyo & 1,037 \\
\hline 007 & Ringinanom & 0,050 & Tempurejo & 1,864 & Bandar Lor & 1,113 \\
\hline 008 & Pakelan & 0,214 & Ketami & 1,894 & Mojoroto & 2.130 \\
\hline 009 & Setonogedong & 0,059 & Pesantren & 1,356 & Sukorame & 4,302 \\
\hline 010 & Kemasan & 0,228 & Bangsal & 1,029 & Bujel & 1.590 \\
\hline 011 & Jagalan & 0,043 & Burengan & 1.283 & Ngampel & 1,468 \\
\hline 012 & \begin{tabular}{|l|} 
Banjaran \\
\end{tabular} & 1,209 & Tinalan & 0,926 & Gayam & 1.296 \\
\hline 013 & Ngadirejo & 1,470 & Pakunden & 1,024 & Mrican & 1,109 \\
\hline 014 & Dandangan & 1.100 & Singonegaran & 0,99 & Dermo & 0,657 \\
\hline 015 & Balowerti & 0,830 & Jamsaren & 1,42 & & \\
\hline 016 & Pocanan & 0,214 & & & & \\
\hline 17 & Semampir & 1,791 & & & & \\
\hline
\end{tabular}

Sumber: BPS, 2017. Kota Kediri Dalam Angka,

Adapun aktivitas ekonomi utama yang dikembangkan di Kota Kediri adalah pada sektor industri, pendidikan, perdagangan dan perdagangan. Selain itu, aktivitas berbagai transportasi dan pembangunan yang dialokasikan pada bagian wilayah kota yang sesuai sesuai dengan perkembangan perkembangannya. Peruntukkan masingmasing bagian wilayah Kota Kediri adalah sebagai berikut: Pertama, pada Bagian Wilayah Kota A (BWK A), terdiri dari seluruh kecamatan Mojoroto dengan luas kawasan 2.460,40 Ha. Kegiatan yang dikembangkan: permukiman, pariwisata, industri dan pendidikan. Kedua, Bagian Wilayah Kota B (BWK B), terdiri dari seluruh wilayah Kecamatan Kota dan sebagian besar Kecamatan Pesantren dengan luas kawasan 2.185,05 Ha. Kegiatan utama yang adalah industri, perdagangan dan perdagangan, perkantoran dan permukiman. Dan ketiga pada Bagian Wilayah Kota C (BWK C), meliputi sebagian besar wilayah Kecamatan Pesantren dengan wilayah yang luas 1.694,98 Ha yang dikembangkan adalah industri dan permukiman (Kotakediri.go.id, 2018). 


\section{Pertumbuhan Ekonomi Kota Kediri IPM Kota Kediri}

Indeks Pembangunan Manusia Kota Kediri selama 5 tahun masih berada di atas rata-rata IPM Provinsi Jawa Timur, dan menempati urutan 5 besar (Kotakediri.go.id, 2018).

Kota Kediri termasuk daerah yang memiliki IPM yang relatif tinggi. IPM Kota Kediri tahun 2011 baru 72.923, tahun 2012 73,66 masih jauh dari harapan. Namun demikian, Indeks pembangunan manusia (IPM) Kota Kediri mengalami peningkatan selama tahun $2013(74,18)$. Pada tahun 2017, semakin meningkat posisi 5 besar IPM tertinggi di Jawa Timur dengan angka 77,13 (Nugroho, 2018). Kalau dilihat perkembangan dari tahun 2014 hingga tahun 2018 tampak sebagai berikut.

Tabel 4. IPM 2014-2018

\begin{tabular}{|l|l|l|}
\hline Tahun & Kota Kediri & Jawa Timur \\
\hline 2014 & 74,62 & 68,14 \\
\hline 2015 & 75.67 & 68.95 \\
\hline 2016 & 76.33 & 68.74 \\
\hline 2017 & 77.13 & 70,27 \\
\hline 2018 & 77,58 & 70,77 \\
\hline
\end{tabular}

Sumber: (Badan Pusat Statistik

2017);(Kotakediri.go.id 2018)

Nilai IPM Kota Kediri tahun 2018 sebesar 77,58 menjadi nilai yang jauh di atas IPM Jwa timur yaitu sebesar 70,77. Sementara untuk komponen pendidikan dari 0,74 menjadi 0,75. Dan nilai stagnan ada pada komponen kesehatan tetap ada di angka 0,83 (Nugroho, 2018). Untuk mempertahankan IPM Kota Kediri tahun 2018 sebesar 77,58, maka peran pemerintah daerah Kota Kediri dan masyarakat harus terus mendukung keberhasilan IPM ini.

\section{Strategi Meningkatkan IPM Kota Kediri}

Tingkat capaian IPM di Kota Kediri masih perlu terus ditingkatkan sesuai harapan semua pihak, yaitu dengan cara sebagai berikut.

Pertama, meningkatkan tingkat pendidikan masyarakat. Sebagaimana diketahui, bahwa harapan lama sekolah masyarakat di Kota Kediri 14,96, rata-rata lama sekolah 9,91, Alokasi anggaran untuk
Dinas Pendidikan baru mencapai $0,2 \%$ atau RP 4,3 Miliar dari total APBD senilai 1,85 triliun di tahun 2018 dan rata-rata dari rentang waktu 2015 sampai dengan 2018 baru mencapai $0,18 \%$, masih sangat jauh dari amanat UU Sisdiknas (20\%). Bila dibandingkan Kabupaten Tulung Agung (7,2\%), Lumajang 9,7\%, anggaran pendidikan Kota Kediri masih sangat tertinggal (Badan Pusat Statistik, 2017). Oleh karena itu, perlu terus ditingkatkan.

Menurut Kemenkeu (2018), "Rendahnya alokasi anggaran dana pendidikan suatu daerah dapat disebabkan oleh beberapa faktor. Salah satu adalah karena kurangnya kemampuan dinas pendidikan wilayah tersebut dalam mengelola anggaran yang disediakan. Padahal untuk mencerdaskan generasi penerus bangsa agar tidak tertinggal dengan negara lain membutuhkan anggaran yang besar. Di negara-negara maju bahkan membebaskan biaya pendidikan hingga ke perguruan tinggi untuk meningkatkan kualitas sumber daya manusia."

Hasil penelitian ini menguatkan temuan Orinbao (2013) yang menyimpulkan bahwa "Faktor-Faktor yang Mempengaruhi Indeks Pembangunan Manusia adalah angka melek huruf /AMH, rata-rata lama sekolah/MYS, angka harapan hidup/L, pengeluaran rill per kapita/PPP, dan kemiskinan/K) (Orinbao, 2013).

Hasil penelitian ini menguatkan temuan Baeti, dkk. (2013) yang menunjukkan bahwa IPM dipengaruhi oleh adalah PDRB perkapita, angka harapan hidup, pengeluaran riil per kapita, angka melek huruf dan rata-rata lama sekolah (Baeti, 2013).

Kedua, meningkatkan tingkat kesehatan masyarakat Kota Kediri. Masih banyaknya kasus gizi buruk menjadi salah satu penyebab rendahnya IPM sehingga masih di bawah rata-rata nasional. Dengan kata lain, aspek kesehatan belum sepenuhnya diperhatikan. Antara News (24 Juli 2019) memberitakan bahwa, ada ratusan anak di Kediri terkena Stunting. Dalam berita itu, Dinas Pendidikan juga 


\section{SUWARNO}

\section{Kebijakan Pengembangan Sumber Daya Manusia Di Kota Kediri Dalam Rangka Peningkatan Indeks Pembangunan Manusia}

menyebutkan bahwa angka stunting di Kota Kediri mencapai $12 \&$ atau ada 600 anak usia balita kurang mendapatkan gizi yang cukup.

Secara rinci Jumlah Sarana dan Tenaga Kesehatan di Kota Kediri Tahun 2018 dapat ditabulasikan sebagai berikut.

Tabel 5. Jumlah Sarana Kesehatan Pemerintah Kota Kediri Tahun 2018

\begin{tabular}{|l|l|c|}
\hline No & \multicolumn{1}{|c|}{ Sarana Kesehatan } & $\begin{array}{c}\text { Jumlah } \\
\text { Negeri }\end{array}$ \\
\hline 1 & RSU & 1 \\
\hline 2 & RS Khusus & 0 \\
\hline 3 & $\begin{array}{l}\text { Gedung Farmasi } \\
\text { Dinkes }\end{array}$ & 1 \\
\hline 4 & Labkesda & 1 \\
\hline 5 & $\begin{array}{l}\text { Kendaraan } \\
\text { Operasional }\end{array}$ & 6 \\
\hline 6 & $\begin{array}{l}\text { Saarana Kesehatan } \\
\text { lainnya }\end{array}$ & \\
\hline
\end{tabular}

Sumber : Dinas Kesehatan 2018

Tabel 6. Jumlah Sarana Kesehatan Swasta Kota Kediri Tahun 2018

\begin{tabular}{|l|l|c|}
\hline No & Sarana Kesehatan & $\begin{array}{c}\text { Jumlah } \\
\text { Negeri }\end{array}$ \\
\hline 1 & RSU & 7 \\
\hline 2 & RS Khusus & 4 \\
\hline 3 & Balai Pengobatan & 10 \\
\hline 4 & Klinik & 30 \\
\hline 5 & $\begin{array}{l}\text { Praktik Kesehatan } \\
\text { Tradisional }\end{array}$ & 153 \\
\hline 6 & $\begin{array}{l}\text { Pedagang besar } \\
\text { farmasi }\end{array}$ & 4 \\
\hline 7 & $\begin{array}{l}\text { Penyalur Alat } \\
\text { Kesehatan }\end{array}$ & 1 \\
\hline 8 & Apotik & 14 \\
\hline 9 & Toko Obat & 1 \\
\hline 10 & Unit Transfusi darah & (Dinas Kesehatan Kota Kedin \\
\hline
\end{tabular}

Sumber: (Dinas Kesehatan Kota Kediri, 2018)

Berdasarkan Tabel 5 dan 6 diketahui bahwa pada tahun 2018 jumlah Rumah sakit pemerintah sebanyak 1, Puskesmas sebanyak 28, Puskesmas Pembantu sebanyak 69, Puskesling sebanyak 19, Posyandu sebanyak 468, Polindes sebanyak
88, dokter sebanyak 354 orang, perwat sebanyak 414 orang, dan bidan sebanyak 3.879 orang.

Dasar pemberdayaan dan kemandirian kesehatan di Kota Kediri adalah, bahwa masyarakat bukan hanya bagian dari obyek namun subyek kegiatan, proyek, program kesehatan yang dilakukan pemerintah daerah. Pleh karena itu, seluruh komponen bertanggung jawab memberdayakan derajat kesehatan (Dinas Kesehatan Kota Kediri, 2018)

Dengan dasar ini melalui kegiatan, proyek, program kesehatan difasilitasi agar mampu mengambil keputusan yang tepat bagi masyarakat yang membutuhkan pelayanan kesehatan. Masyarakat harus meningkatkan rasa solidaritasnya terhadap lingkungan dan sesama individu agar dapat menjangkau fasilitas kesehatan. Disisi lain, penting bahwa fasilitas pelayanan kesehatan yang berkualitas dengna biaya lebih terjangkau juga harus sesuai dengan norma sosial budaya setempat serta tepat waktu (Dinas Kesehatan Kota Kediri, 2018).

Hasil penelitian ini menguatkan temuan Kacaribu (2013: 1) menyimpulkan bahwa Produk Domestik Regional Bruto, Pengeluaran pemerintah daerah berdasarkan padafungsi pendidikan, rasio kemiskinan terhadap jumlah penduduk yang ada, rasio jumlah penduduk terhadap jumlah dokter di suatu wilayah, rasio jumlah penduduk terhadap jumlah bidan, rasio jumlah penduduk terhadap jumlah perawat, rasio peserta didik terhadap pengajar mempengaruhi IPM (Kacaribu, 2013).

Selanjutnya adalah dengan menjalankan program pembangunan yang berkeadilan dan mampu mengurangi angka kemiskinan. Pertumbuhan Ekonomi di ukur untuk mengetahui perubahan kondisi ekonomi dan sebagai indikasi keberhasilan pembangunan ekonomi suatu daerah, Pertumbuhan ekonomi Kota Kediri selama 5 tahun cukup fluktuatif, namun masih lebih baik bila dibandingkan dengan pertumbuhan Ekonomi tingkat Nasional. 
Tabel 7. Pertumbuhan ekonomi Tahun 2014-2018

\begin{tabular}{|l|l|l|}
\hline Tahun & $\begin{array}{l}\text { Kota Kediri } \\
(\%)\end{array}$ & Nasional (\%) \\
\hline 2014 & 5,85 & 5,01 \\
\hline 2015 & 5,36 & 4,88 \\
\hline 2016 & 5,54 & 5,03 \\
\hline 2017 & 5,14 & 5,07 \\
\hline 2018 & 5,42 & 5,17 \\
\hline
\end{tabular}

Sumber: (Pemerintah Kota Kediri, 2019)

Pada tahun 2018 Kota Kediri mendapat penghargaan TPID (Tim Pengendali Inflasi Daerah) terbaik se-jawa bali dimana tingkat inflasi pada tahun 2018 sebesar $1.97 \%$ dan merupakan yang terendah se-jawa bali. Pada tahun 2018 Kota Kediri mendapat penghargaan TPID (Tim Pengendali Inflasi Daerah) terbaik se-jawa bali dimana tingkat inflasi pada tahun 2018 sebesar $1.97 \%$ dan merupakan yang terendah se-Jawa Bali.

Tabel 8. Inflasi Kota Kediri, Jawa Timur, dan Nasional tahun 2014-2018

\begin{tabular}{|c|c|c|c|}
\hline Tahun & $\begin{array}{c}\text { Kota } \\
\text { Kediri } \\
(\%)\end{array}$ & $\begin{array}{c}\text { Jawa } \\
\text { Timur } \\
(\%)\end{array}$ & $\begin{array}{c}\text { Nasional } \\
(\%)\end{array}$ \\
\hline 2014 & 7,49 & 7,77 & 8,36 \\
\hline 2015 & 1,71 & 3,08 & 3,35 \\
\hline 2016 & 1,3 & 3,02 & 3,02 \\
\hline 2017 & 3,44 & 4,04 & 3,61 \\
\hline 2018 & 1,97 & 2,86 & 3,13 \\
\hline
\end{tabular}

Sumber: (Pemerintah Kota Kediri, 2019)

PDRB per kapita bermanfaat sebagai indikator standar hidup atau kesejahteraan suatu daerah dari tahun ke tahun, menjadi pembanding kesejahteraan antar daerah, serta digunakan sebagai pedoman dalam pengambilan kebijakan ekonomi daerah. nilai PDRB per Kapita ADHB Kota Kediri dari tahun 2014 hingga tahun 2018 terus mengalami peningkatan, baik PDRB dengan PT Gudang Garam Tbk. ataupun tanpa PT Gudang Garam Tbk. Hal ini menunjukkan bahwa kesejahteraan masyarakat Kota Kediri dari tahun ke tahun semakin meningkat.
Hasil penelitian ini menguatkan temuan Melliana dan Zain (2013) yang menyimpulkan bahwa, indikator yang mampu mempengaruhi Indeks Pembangunan Manusia adalah angka partisipasi sekolah (APS), jumlah sarana kesehatan di wilayah tersebut, persentase rumah tangga individu dengan akses air bersih yang dapa diperoleh serta tingkat partisipasi angkatan kerja (TPAK), dan PDRB perkapita.

Hasil penelitian ini menguatkan temuan Sjafari, dkk (2015) yang menyimpulkan bahwa, IPM dipengaruhi oleh 5 (lima) hal, yaitu: (1) angka pengangguran; (2) angka kemiskinan; (3) tingkat inflasi; (4) nilai tambah produk hasil pertanian; (5) daya saing SDM, dan PDRB.

Keempat, Meningkatkan taraf hidup masyarakat dengan cara mengurang tingkat kemiskinan dan tingkat pengangguran di Kota Kediri.

Tabel 9. Tingkat Kemiskinan tahun 20142018

\begin{tabular}{|c|c|c|}
\hline Tahun & Kota Kediri & Jawa Timur \\
\hline 2014 & 7,95 & 11,25 \\
\hline 2015 & 8,51 & 11,22 \\
\hline 2016 & 8,4 & 10,86 \\
\hline 2017 & 8,49 & 10,64 \\
\hline 2018 & 7,68 & 9,82 \\
\hline
\end{tabular}

Sumber: (Pemerintah Kota Kediri, 2019)

Tabel 9 menunjukkan bahwa, tingkat kemiskinan kota Kediri selalu di bawah tingkat kemiskinan di Jawa Timur, sehingga dapat dikatakan rata-rata orang miskin di kediri Jauh di bawah rata-rata Jawa Timur.

Tabel 10. Tingkat Pengangguran di Kota Kediri 2014-2018

\begin{tabular}{|c|c|c|}
\hline Tahun & Kota Kediri & Jawa Timur \\
\hline 2014 & 7,66 & 4,19 \\
\hline 2015 & 8,46 & 4,47 \\
\hline 2016 & 8,46 & 4,21 \\
\hline 2017 & 4,68 & 4,0 \\
\hline 2018 & 3,63 & 3,99 \\
\hline
\end{tabular}

Sumber: (Pemerintah Kota Kediri, 2019) 


\section{SUWARNO \\ Kebijakan Pengembangan Sumber Daya Manusia Di Kota Kediri Dalam Rangka Peningkatan Indeks Pembangunan Manusia}

Menurut Nugroho, (2018) kemiskinan di Kota Kediri Turun, hal itu sebagai akibat stabilitas inflasi di Daerah, khususnya di Kota Kediri. Bahkan tahun 2018 merupakan angka terendah dalam sejarah. Menurut Data BPS, angka kemiskinan di Kota Kediri hanya $7,68 \%$, mengalami penurunan signifikan dibandingkan tahun 2017 yang mencapai $8,49 \%$. Secara nasional, jumlah penduduk miskin di Indonesia sebesar 9,82 persen (Nugroho, 2019).

Selain angka kemiskinan terdapat indikator batas kemiskinan yang meningkat dari tahun sebelumnya. Jika pada 2017 batasnya adalah Rp 420.712 per kapita/bulan maka 2018 naik menjadi Rp 453.807 per kapita/bulan. Pemkot Kediri terus memfasilitasi program-program yang dapat mengentaskan kemiskinan antara lain adalah Bantuan Langsung Sementara Masyarakat (BLSM), Rumah Tidak Layak Huni (RTLH) (Pemerintah Kota Kediri, 2019).

Program tersebut secara spesifik belum mampu diimplemetasikan dengan masksimal terutama dalam hal: (1) pelaksanaan program pembangunan yang pro rakyat belum sepenuhnya dapat dilaksanakan, dalam hal ini belum ada program penanggulangan kemiskinan yang berbasis keluarga, pembukaan lapangan kerja baru, pemberdayaan masyarakat, dan pemberdayaan UMKM secara maksimal; (2) pelaksanaan program pembangunan yang adil belum dapat merata dan dirasakan oleh semua lapisan masyarakat, dalam hal ini belum memprioritaskan anakanak, perempuan, keluarga miskin, dan orang terpinggirkan; dan (3) pelaksanaan program pembangunan untuk mencapai target-target MDGs belum mampu memenuhi berbagai indikator MDGs yang dijadikan sebagai indikator keberhasilan pembangunan.

Bila dilihat dari perkembangan angka kemiskinan dalam periode tahun 2011- 2015 dapat dikatakan turun secara signifikan hingga 5,98\%, namun masih lebih tinggi dibandingkan provinsi di Jawa lainnya yang mayoritas dibawah (5\%).
Data angka pengangguran di Kota Kediri Turun di bawah Jawa Timur. Bila menilik ke belakang, pada tahun 2014, angka perolehan terbuka di Kota Kediri sebesar 7,66 persen dan Provinsi Jawa Timur 4,49 persen. Tahun 2015, angka pembelian Kota Kediri berada di angka 8,46 persen dan Provinsi Jawa Timur di angka 4,47 persen. Tahun 2017, meraih di Kota Kediri mencapai 4,68 persen dan Provinsi Jawa Timur 4,00 persen.

Tahun 2018, Kota Kediri berhasil melepaskan kemiskinan sebesar 7,68 persen berdasarkan rilis resmi Badan Pusat Statistik (BPS). Bila menilik ke belakang, pada tahun 2014, angka perolehan terbuka di Kota Kediri sebesar 7,66 persen dan Provinsi Jawa Timur 4,49 persen. Tahun 2015, angka pembelian Kota Kediri berada di angka 8,46 persen dan Provinsi Jawa Timur di angka 4,47 persen. Tahun 2017, meraih di Kota Kediri mencapai 4,68 persen dan Provinsi Jawa Timur 4,00 persen.

Jumlah penduduk miskin di Kota Kediri semakin berkurang dari tahun 2017 yang berarti angka 8,49 persen. Penurunan kemiskinan di Kota Kediri pada 2018 berada di bawah capaian nasional sebesar 9,82 persen dan capaian Jawa Timur sebesar 10,98 persen. Sementara untuk tingkat perolehan terbuka, Kota Kediri meningkatkan penurunan sebesar 1,05 persen dibandingkan dengan tahun sebelumnya yang berada di angka 4,68 persen. Selain itu, pada 2017, pertumbuhan ekonomi Kota Kediri non-industri tembakau mencapai 7,02 persen atau meningkat sebesar 0,80 persen dari tahun sebelumnya sebesar 6,22 persen.

Sedangkan, perputaran Kota Kediri tahun 2018 sebesar 1,97 persen (yoy) atau lebih rendah jika dibandingkan dengan tahun sebelumnya sebesar 3,44 persen (yoy). Rata-rata Kota Kediri tahun 2018 terendah se-Jawa-Bali.

Hingga saat ini, Pemerintah Kota Kediri terus menyediakan program-program yang dapat mengentaskan kemiskinan dan menerima terbuka. Beberapa program dan inovasi Pemerintah Kota Kediri antara lain 
BLSM, RS-RTLH, santunan kematian, rastrada, OPM, santunan anak yatim, bansos untuk orang dengan kecacatan berat. Juga jamkesda, ASLUT, beasiswa warga miskin, sekolah gratis, beasiswa bagi siswa miskin berprestasi, seragam gratis, bahasa Inggris masif, program kewaspadaan pangan dan keamanan pangan, Prodamas, Gemakiba, bantuan bantuan untuk keluarga pasien, dan kunjungan rumah.

Hasil penelitian ini sesuai dengan temuan Dendi, Shivakoti, dan Ranamukhaarachchi, (2004) yang menyimpulkan bahwa, Indeks Pembangunan Manusia, dipengaruhi oleh PDRB per kapita, dan jumlah pengangguran terhadap jumlah penduduk miskin. Hasil penelitian ini juga sesuai dengan temuan Kaswinata, (2016) yang menyimpulkan bahwa perkembangan IPM dipengaruhi oleh keberhasilan mengentaskan kemiskinan (KMS), meningkatkan pertumbuhan ekonomi (GRWT) dan meningkatkan belanja modal (lnBMOD).

Kelima, meningkatkan upah tenaga kerja (UMK) di tingkat kota. UMK Kota Kediri Rp. 2.060.925,00. Berikut UMP Jawa Timur selama 5 tahun terakhir:

\section{Tabel 11. Upah tenaga kerja (UMK)}

\begin{tabular}{|l|l|}
\hline Tahun & RP \\
\hline Ump Jatim 2020 & Rp 1.768.777,00 \\
\hline Ump Jatim 2019 & $\operatorname{Rp~1.630.059,05~}$ \\
\hline Ump Jatim 2018 & Rp 1.508.894,80 \\
\hline Ump Jatim 2017 & Rp 1.388.000,00 \\
\hline Ump Jatim 2016 & Rp 1.283.000,00 \\
\hline
\end{tabular}

Sumber: (Nugroho, 2018)

Hasil penelitian ini sejalan dengan penelitian hasil temuan lainnya yang mengungkapkan bahwa ekonomi lokal lebih diarahkan pada dinamika usaha dalam pembangunan wilayah dan menekankan pada dimensi peningkatan kesempatan kerja serta pendapatan masyarakat. Memberdayakan ekonomi lokal adalah merupakan suatu proses dimana Pemerintah Daerah dan/atau kelompok berbasis komunitas mengelola sumber daya yang ada dan masuk kepada penataan kemitraan baru dengan sektor swasta, atau diantara mereka sendiri, untuk menciptakan pekerjaan baru dan merangsang kegiatan ekonomi wilayah dengan cara meningkatkan pendapatan mereka (Sugiharto, 2007).

Berdasarkan literatur sebelumnya yang mengungkapkan bahwa pertumbuhan ekonomi tidak berkontribusi pada pembangunan maunsia. Nampaknya hal ini secara khusus dikarenakan efek perang dan terorisme di suatu wilayah. Memang, terorisme mempunyai dampak buruk pada kehidupan manusia (Sinha and Sen, 2016). Ditambah lagi, efek perang deskriptif datang dalam bentuk perpindahan penduduk, perusakan inftrastruktur pendidkan dan rumah sakit mempengaruhi pendidikan, kesehatan, dan lingkungan. Efek gabungan inilah yang mengarah pada kemiskinan dan pembangunan manusia yang rendah (Miguel and Roland 2011); (Estrada et al. 2015); (Durodie 2016). Oleh karena itu, sangat penting untuk pengembangan sumber daya manusia sebaik mungkin apabila menginginkan agar meningkatnya indeks pengembangan manusia secara berkelanjutan di Indonesia, khususnya Kota Kediri. Hal ini dilakukan dengan melibatkan tiga dimensi pembangunan berkelanjutan yaitu mengkooordinasikan pembangunan dimensi ekonomi, sosial dan lingkungan, untuk menyeimbangkan kesejahteraan intragenerasi, dan untuk memaksimalkan total kesejahteraan generasi (Jin et al. 2020). Dengan begitu, para pemangku kepentingan dapat mengkoordinasikan kesejahteraan antara generasi sekarang dan masa depan, tanpa harus merusak kesejahteraan generasi masa depan atau melepaskan pemanfaatan sember daya yang wajar demi kesejahteraan generasi masa depan.

\section{KESIMPULAN}

Berdasarkan hasil penelitian dan pembahasan dapat disimpulkan bahwa, kebijakan pengembangan sumber daya manusia di Kota Kediri dalam rangka peningkatan Indek Pembangunan Manusia sudah berjalan dengan sangat baik, terbukti, IPK Kota Kediri selama 5 tahun terahir 


\section{SUWARNO \\ Kebijakan Pengembangan Sumber Daya Manusia Di Kota Kediri Dalam Rangka Peningkatan Indeks Pembangunan Manusia}

selalu di atas rata-rata Jawa Timur, dan Nasional. Hal itu berkat adanya usaha yang sungguh-sungguh dalam meningkatkan tingkat pendidikan masyarakat, tingkat kesehatan masyarakat, tingkat pendapatan masyarakat, upaya pengentasan kemiskinan, peningkatkan PDRB, dan berbagai usaha lain yang bersifat simultan dan terus menurus. Sebagai implikasi teoritis, penelitian tentang pengembangan sumber daya manusia secara empiris membutuhkan dukungan dari faktor pendidikan dan kesehatan yang berasal dari para pemangku kepentingan khususnya kebijakan pemerintah daerah. Sedangkan secara praktis, penelitian ini diharapkan berkontribusi terhadap kajian tentang pembangunan sumber daya manusia sebagai upaya pengentasan kemiskinan.

\section{DAFTAR PUSTAKA}

Badan Pusat Statistik. 2017. Kota Kediri Dalam Angka. Kediri: BPS Kota Kediri.

Baeti, Nur. 2013. "Pengaruh Pengangguran, Pertumbuhan Ekonomi, Dan Pengeluaran Pemerintah Terhadap Pembangunan Manusia Kabupaten/Kota Di Provinsi Jawa Tengah Tahun 2007-2011." Economics Development Analysis Journal 2 (3): 85-98. https://doi.org/10.15294/edaj.v2i3.198 4.

Basrowi, and Suseno. 2016. "IPM Provinsi Banten." Banten: Sekretariat Daerah.

Dinas Kesehatan Kota Kediri. 2018. "Resntra SKPD Kesehatan." Www.Dinkes.Kedirikab.Go.Id. 2018. http://www.dinkes.kedirikab.go.id/kon ten/renstra/74336Rencana Strategis SKPD Dinkes Kab Kediri Tahun 2016 - 2021.pdf.

Durodie, Bill. 2016. "Securitising Education to Prevent Terrorism or Losing Direction?" British Journal of Educational Studies 64 (1): 21-35. https://doi.org/10.1080/00071005.201 5.1107023
Estrada, Mario Arturo Ruiz, Donghyun Park, Jung Suk Kim, and Alam Khan. 2015. "The Economic Impact of Terrorism: A New Model and Its Application to Pakistan." Journal of Policy Modeling 37 (6): 1065-80. https://doi.org/10.1016/j.jpolmod.2015 .08.004.

Faisal, Sanapiah. 1992. Peneliti Kualitatif: Dasar- Dasar Dan Aplikasi. Malang: UM Press.

Hou, Jack, Patrick Paul Walsh, and Jing Zhang. 2015. "The Dynamics of Human Development Index." Social Science Journal 52 (3): 331-47. https://doi.org/10.1016/j.soscij.2014.0 7.003 .

Iskandar, Irham. 2017. "Effect Of Human Development Index Fund on Economic Growth Through A Special Autonomy." Jurnal Ekonomi Pembangunan: Kajian Masalah Ekonomi Dan Pembangunan 18 (1): 50 .

https://doi.org/10.23917/jep.v18i1.292 0 .

Javaid, Anam. 2019. "A Review on Human Development Index A Review on Human Development Index" 6 (October): 357-69.

Jin, Hui, Xinyi Qian, Tachia Chin, and Hejie Zhang. 2020. "A Global Assessment of Sustainable Development Based on Modification of the Human Development Index via the Entropy Method." Sustainability (Switzerland) 12 https://doi.org/10.3390/SU12083251.

Kacaribu, Rosinta Dewi. 2013. "Analisis Indeks Pembangunan Manusia Dan Faktor -Faktor Yang Memengaruhi Di Provinsi Papua." Institut Pertanian Bogor.

Khan, Noor Hashim, Yanbing Ju, and Syed Tauseef Hassan. 2018. "Modeling the Impact of Economic Growth and Terrorism on the Human Development Index: Collecting Evidence from Pakistan." Environmental Science and Pollution Research 25 (34): 34661- 
73. https://doi.org/10.1007/s11356018-3275-5.

Kintamani, Ida. 2008. "Analisis Indeks Pembangunan Manusia." Jurnal Pendidikan Dan Kebudayaan 14 (72): 37-421.

Kotakediri.go.id. 2018. Pemerintah Kota Kediri. Kediri: Databook.

Maryani, Tri. 2010. Analisis Indeks Pembangunan Manusia Di Provinsi Jawa Tengah. Yogyakarta: UPN Veteran.

Melliana, Ayunanda, and Ismaini Zain. 2013. "Indeks Pembangunan Manusia Di Kabupaten / Kota Provinsi Jawa Timur Dengan Menggunakan Regresi Panel." Jurnal Sains Dan Seni Pomits 2 (2): 237-42.

Miguel, Edward, and Gérard Roland. 2011. "The Long-Run Impact of Bombing Vietnam." Journal of Development Economics 96 (1): 1-15. https://doi.org/10.1016/j.jdeveco.2010. 07.004 .

Nevi, Hendri. 2015. Indeks Pembangunan Manusia (IPM) Metode Baru. Naaskah Power Point. Soreang: BPS. Soreang: Badan Pusat Statistik.

Nugroho, Adi. 2018. "Nilai IPM Kota Kediri Lampaui Jatim Dan Nasional, Ini Datanya. Radar Kediri." Journal of Materials Processing Technology. 2018.

. 2019. "Kemiskinan Di Kota Kediri Turun, Pengaruh Stabilitas Inflasi Daerah." Radarkediri.Jawapos.Com. 2019.

https://radarkediri.jawapos.com/read/2 019/01/08/112361/kemiskinan-kotakediri-turun-pengaruh- stabilitasinflasi-daerah.
Orinbao, Arita Adelheid M. 2013. "FaktorFaktor Yang Mempengaruhi Indeks Pembangunan Manusia Di Provinsi Papua Barat Tahun 2006-2009." Universitas Atma Jaya Yogyakarta (UAJY).

Pemerintah Kota Kediri. 2019. "Profil Pembangunan Kota Kediri 2019." 2019.

Singarimbun, M., and S Effendi. 1989. Metode Penelitian Survei. Jakarta: LP3ES.

Sinha, Avik, and Sudipta Sen. 2016. "Atmospheric Consequences of Trade and Human Development: A Case of BRIC Countries." Atmospheric Pollution Research 7 (6): 980-89. https://doi.org/10.1016/j.apr.2016.06.0 03.

Sugiharto, Slamet. 2007. Komitmen Pembangunan Manusia." Karya Ilmiah Widyaiswara Indonesia Dan Balai Diklat Keuangan III Yogyakarta. Yogyakarta: Balai Diklat Keuangan III.

Susanto, Arif Budi, and Lucky Rachmawati. 2010. Pengaruh Indeks Pembangunan Manusia (Ipm) Dan Inflasi Terhadap Pertumbuhan Ekonomi Di Kabupaten Lamongan. Surabaya: UNESA.

Syarifah. 2012. "Faktor-faktor Yang Mempengaruhi Indeks Pembangunan Manusia Di Indonesia Tahun 20052009." Universits Negeri Semarang.

United Nations Development Programme (UNDP). 2014. "Sustaining Human Progress: Reducing Vulnerabilities and Building Resilience." In Human Development Report 2014. New York, USA: United Nations Development Programme. 